\title{
SOME NOTES ON TWO CHINESE DRESS ORNAMENTS IN THE RIJKSMUSEUM
}

In the Rijksmuseum Amsterdam are two Chinese dress ornaments (fig. 1) which belong to the long term loan from the collection of the VVAK. They are two plaques made of reticulated gold, attached to a slightly thicker base of gilt bronze. The rectangular one is decorated with an animal head (probably a tiger) and the other "mountain-shaped' plaque is decorated with a winged insect. Both creatures' eyes are inlaid with semi-precious stones identified as turquoise. According to their style, they should belong to the same period of manufacture. This article deals with the issues of dating, iconography, function and the craft techniques used.

\section{Dating}

The dating of the 'mountain-shaped' plaque is various. The two Amsterdam plaques were first dated by H.F.E. Visser in 1935 and attributed to the period of the Six Dynasties (220-589). ${ }^{2}$ Visser's opinion was widely accepted. In 1955, the Japanese scholar Umehara also dated two similar 'mountain-shaped' plaques decorated with winged insects in the collection of the Museum Yamato Bunkakan in Nara to the Six Dynasties ${ }^{3}$ while Bo Gyllensvärd again dated a similar 'mountain-shaped' plaque from the Stockholm collection to the same period. ${ }^{4}$ In the exhibition Early Chinese Gold \& Silver in 1972, Paul Singer also attributed a comparable piece from the collection of the Metropolitan Museum to the Six Dynasties, ${ }^{5}$ and in an exhibition held at Osaka in 1975, two similar pieces were exhibited, one of them belonging to the collection of the Hakkaku Art Museum, Kobe; both were dated to the same Six Dynasties period. ${ }^{6}$

However, in the 1985 catalogue of the Rijksmuseum collection, A.H. van der Meijden overruled Visser's dating and considered these two plaques to be objects from the Eastern Han dynasty (25-220), dating to the early 3rd century. ${ }^{7}$

Archeological excavations can help us clarify this ambiguity in the dating. Three similar examples of 'mountain-shaped' plaques have been excavated from tombs in the Northern barbarian states. One comes from an early Jin (265-420) grave at Dunhuang in Gansu province excavated in 1960 (fig. 2). The grave is attributed to Fan Xinrong and can be dated by an inscription to $369 .{ }^{8}$ The other two (one depicting a winged insect and the other a seated figure with flames surrounding his back, presumably a Buddha) came from an early 5th century Northern Yan (409-436) grave at Beipiao in Liaoning province excavated in 1965 (fig. 3). The identification of the owner of the grave is revealed as Fong Sufu, according to four excavated gold seals, thus the grave can be dated to $415 .{ }^{9}$ Combining thewinformation provided by thesse $e_{11: 59: 57 \mathrm{Am}}$ 
two archeological excavations, the Amsterdam 'mountain-shaped' plaque should be dated to 350-450.The other rectangular plaque decorated with a tiger is in the same style and should also be dated to the same time-frame.

It is worth mentioning that in the 1975 exhibition catalogue, Art of the Six Dynasties: Century of Change and Innovation, Annette L. Juliano has already used information from these archeological excavations to date a similar piece in the collection of the Minneapolis Institute of Arts to the 4th-5th century; ${ }^{10}$ moreover, the 1994 catalogue of Chinese gold and silver wares in the Museum Rietberg in Zürich includes a similar example dated to the Northern Dynasties of the 4th-5th century. ${ }^{11}$ Thus, it is clear that the dating of these two plaques in the Rijksmuseum should be corrected. The archeological excavations also validate the opinion of H.F.E. Visser, the first curator of Asian art in Amsterdam, and demonstrate his outstanding ability in connoisseurship; it was remarkable for him to be able to date these two plaques in 1935 as objects from the Six Dynasties.

Fig. 2 (left)

'Mountain-shaped' plaque decorated with a winged insect motif, excavated at Dunhuang, Gansu province, 1960

Fig. 3

'Mountain-shaped' plaque decorated with a winged insect motif, excavated at Beipiao, Liaoning province, 1965
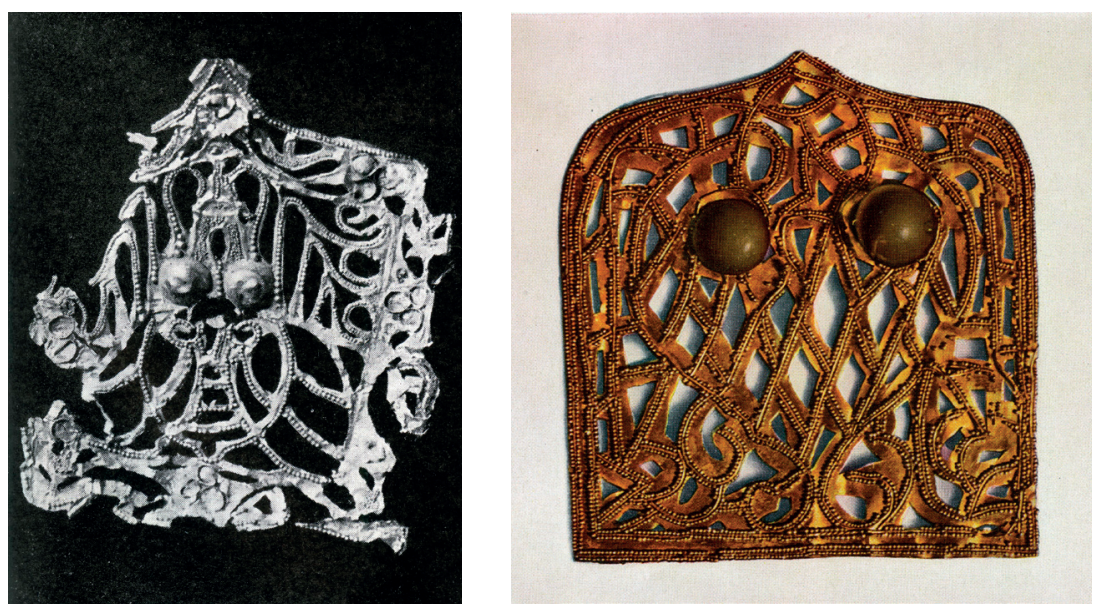

\section{Iconography}

What is the winged insect depicted on the 'mountain-shaped' plaque? According to the archeological reports on both excavations, this winged insect is identified as a cicada. ${ }^{12}$ This opinion is widely accepted by scholars. The cicada has been depicted in Chinese art since the Neolithic. As a decorative motif, the cicada also appears frequently on bronzes from the Shang Dynasty $(1750-1040$ BC) to the Western Zhou Dynasty (1040 - 771 BC). During the Han Dynasty (206 BC - 220 AD), cicada-shaped jades were often placed in tombs. This symbolism is understandable when we consider the life cycle of the cicada: when the eggs hatch, the newly hatched nymphs drop to the ground, where they begin to burrow. Cicadas live underground as nymphs for most of their lives, but in the final nymphal instar they construct an exit tunnel to the surface and emerge. They then moult (shed their skins) on a nearby plant for the last time and emerge as adults. This process is used as a metaphor for 'ascending to heaven and becoming an immortal'; thus the cicada-shaped jades were usually placed in the mouth of the dead in tombs of

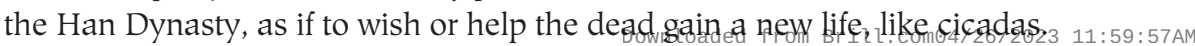


Fig. 4

Attributed to Yan Liben, Thirteen Emperors, detail, Museum of Fine Arts, Boston

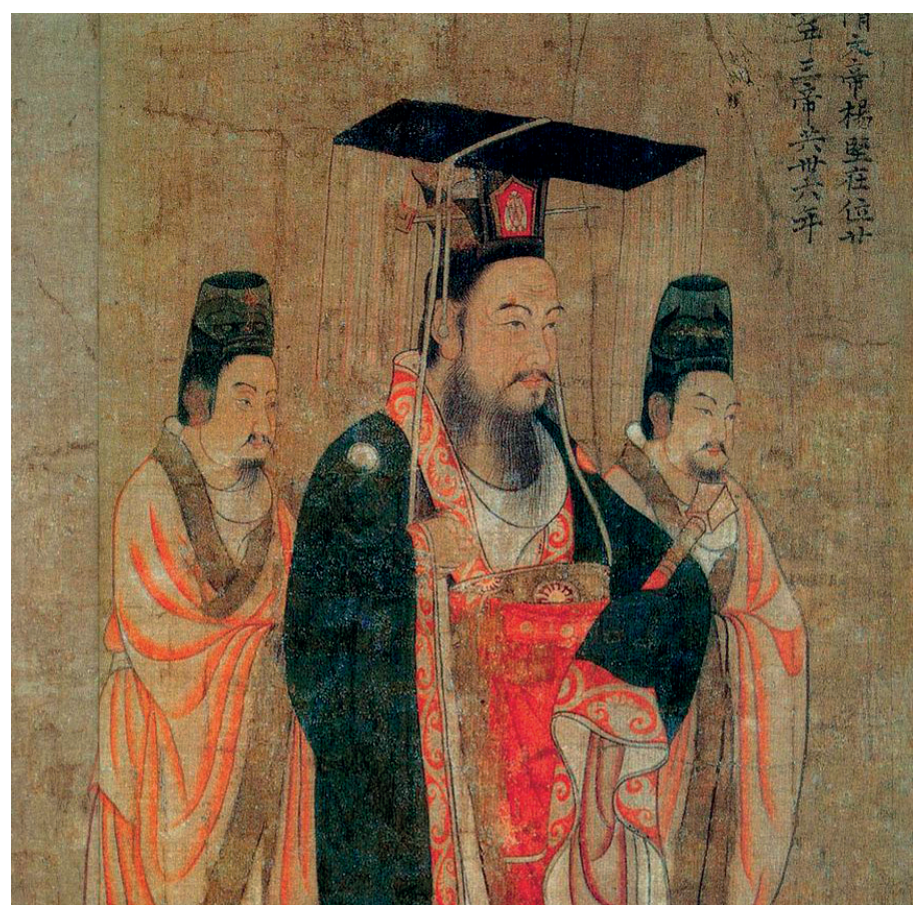

\section{Function}

Judging from its form, the rectangular plaque (AK-MAK-40) should be part of the decoration on a belt. Originally, there would have been several plaques of the same shape (perhaps also with the same motif) decorating the length of a belt made from leather or textile. As for the 'mountain-shaped' plaque (AKMAK-41), it should be a decoration that was placed on the central and frontal side of a hat or crown (maozheng). This can be verified by a depiction in the scroll Thirteen Emperors attributed to Yan Liben (601-673) from the Tang Dynasty (618-907), now in the collection of the Museum of Fine Arts, Boston (fig. 4). ${ }^{13}$ Due to the diet of cicadas - they drink sap from trees, including oak, cypress, willow, ash, and maple - the image of the cicada also signifies the noble character of an officer who stands aloof from politics and material pursuits. In the Book of Later Han (Houhan shu) and Book of Jin (Jin shu), both document the cicada-shaped ornament as a decoration on an officer's hat or crown. ${ }^{14}$

\section{Craft Technique}

From the perspective of technique, the granular and filigree work on these two plaques can be seen as a continuation of the craft of the Han goldsmith. As Juliano suggests, this craftwork also penetrated Korea; a similar Korean example being found in a Paekche grave in Harada. ${ }^{15}$ The significance of these two Amsterdam plaques is that they offer a much broader scope for us when considering the techniques of the Chinese goldsmith and their relationships and expansion throughout the whole of East Asia.

- Ching-Ling Wang is curator of Chinese art in the Müseum für Asiatische Kunst, Staatliche Museen zu Berlin. 


\section{Bibliography}

Helmut Brinker and François Louis, Chinesisches Gold und Silber: Die Sammlung Pierre Uldry, Zürich, Museum Rietberg, 1994.

Dunhuang wenwu yanjiusuo kaoguzu, 'Dunhuang Jinmu’, Kaogu, no. 3 (1974), pp. 191-9.

Fan Ye, Houhan shu [Book of Later Han], reprint: Taipei, Dingwen, 1981. [Originally published 5th century.]

Fang Xuanling, Jin shu [Book of Jin], reprint: Beijing, Zhonghua, 1974. [Originally published 648.]

Bo Gyllensvärd, Chinese Gold \& Silver in the Carl Kempe Collection, Stockholm, Nordisk Rotogravyr, 1953.

Annette L. Juliano, Art of the Six Dynasties: Century of Change and Innovation, New York, China Institute in America, 1975.

Li Yaobo, 'Liaoning beipiao xian xiguan yingzi beiyan Fong Sufu mu', [The Northern Yan grave of Fong Sufu excavated at Xiguan Yingzi, Beipiao county, Liaoning Province], Wenwu, no. 3 (1973), pp. 2-28.

Pauline Lunsingh Scheurleer (ed.), Asiatic Art in the Rijksmuseum, Amsterdam, Vereniging van Vrienden der Aziatische Kunst and Meulenhoff/Landshoff, Amsterdam, 1985.

Osaka Municipal Museum, Rikucho no Bijutsu [Art of the Six Dynasties], Osaka, Osaka Municipal Museum, 1975.

Paul Singer, Early Chinese Gold \& Silver, New York, The China Institute in America, 1972.

Sueji Umehara, 'Gold Granulation Works of the Han and Six Dynasties Period', Yamato Bunka, 16 (1955), pp. 68-75.

H.F.E. Visser, 'Twee Chineesche appliques in granulatietechnick', Maandblad voor Beeldende Kunsten, no. 7 (1935), pp. 221-4.

\section{Notes}

1. Other scholars describe it as 'leaf-shaped', see: Brinker and Louis 1994: 139. I have no better way to describe this shape, so I follow the term provided by the Chinese archeologists, see: Dunhuang wenwu yanjiusuo kaoguzu 1974: 191-9; Li 1973: 2-28.

2. Visser 1935: 221-4.

3. Umehara 1955: 72-3.

4. Gyllensvärd 1953: 78-9.

5. Singer 1972: 30.

6. Osaka Municipal Museum 1975: 17, 50.

7. Scheurleer 1985: 44.

8. Dunhuang wenwu yanjiusuo kaoguzu 1974: 197.

9. Li 1973: 10 .

10. Juliano 1975: 32 .

11. Brinker and Louis 1994: 139.

12. Dunhuang wenwu yanjiusuo kaoguzu 1974: 197; Li 1973: 10.

13. This is not my discovery, as Umehara is the first scholar who points this out. In his article, he suggests that the cicada-shaped ornament is the decoration of a King's or Emperor's crown. See: Umehara 1955: 74-5.

14. Fan 1981: 3668; Fang 1974: 768.

15. Juliano 1975: 32 . 